\title{
The Christopher Clunis enquiry
}

\author{
Jeremy W. Coid
}

On Thursday, 17 December 1992, Jonathan Zito was travelling home by London Underground with his brother Christopher. Jonathan had met his family at Gatwick Airport and there had been insufficient room in his friend's car, so the rest of the family had gone on ahead. The brothers stood waiting for a change of train on the Piccadilly Line at Finsbury Park Station, chatting to each other in a crowd of waiting passengers. On the platform was a large, shabbily dressed, black man acting in a bizarre manner. In the era of community care, floridly psychotic persons are not an unusual sight on the streets of the capital or on its transport services. The waiting passengers ignored Christopher Clunis until he came very close behind the Zito brothers on the edge of the platform. Without any warning, Clunis suddenly stabbed Jonathan Zito three times in the face, one of the wounds penetrating upwards over his eye and into his brain. Clunis was a paranoid schizophrenic. He had occupied a filthy bedsit where a quantity of prescribed medication which he had not been taking was found by the police. There were various items of correspondence from both hospitals and the social services. At his trial he was subsequently found guilty of manslaughter due to diminished responsibility and admitted to Rampton maximum security hospital under Section 37/41 of the Mental Health Act, 1983. Clunis was receiving ongoing community care and supervision from both psychiatric and social services at the time he committed the offence.

The enquiry (Ritchie et al, 1994) revealed a "catalogue of failure" in its assessment of the care that Clunis had received. Its publication was largely due to the tireless efforts of his widow Jayne, alded by a media campaign spearheaded by The Independent newspaper. The Independent had carried out its own investigation into the circumstances and had published them in a full page article on 19 July 1993 (Waterhouse \& Williams, 1993). The same month, the North East and South East Thames Regional Health Authorities set up an investigation into the care and treatment Clunis had received in the months before the killing. They sought to examine the quality of inter-agency collaboration, examine individual responsibilities, and to make recom- mendations for future delivery of care to people in similar circumstances.

This paper examines the implications of the Clunis Report for psychiatrists in the future. The report is an indictment of community psychiatric care in London. It should be read by all psychiatrists as it questions many of our current policies for community psychiatric care of the severely mentally $\mathrm{lll}$.

\section{Passing the parcel}

Many psychiatrists currently practising in the Greater London Area will personally know a colleague who was directly involved in the care of Christopher Clunis. The report sets out in painstaking detail his movements over a $5 \frac{1}{2}$ year period, between June 1987 and the homicide in December in 1992. For brief periods, including a gap of several months between 1988 and 1989. he disappeared without contact. Most importantly, it reveals the circumstances in which he moved from one location to another. During the overall period he was assessed by, or directly under the care of, no less than 30 named psychiatrists (several others are unnamed), 10 of whom were consultants. He recetved 10 episodes of in-patient care, sometimes with transfers between units during a single admission, and was remanded into prison or police custody on three separate occasions. He also lived in one bail hostel, two rehabilitation hostels, two hostels for the homeless, and six separate bed and breakfast accommodations. The geographical pattern of his movements are of considerable interest. He crossed the River Thames from one side of the city to another on four occasions, either by chance or deliberate placement, and with additional sideways moves between different in-patient and aftercare services. He meanwhile passed through three out of the four former Thames Regional Health Authorities.

The report reveals little continuity of care between individual carers as he moved between these different locations. Dangerous or unacceptable behaviour would lead to moves of accommodation, with inevitable changes of catchment area clinical responsibility, leading to yet another team of sometimes poorly coordinated, sometimes reluctant, community 
carers having to take clinical responsibility. Two hospitals discharged him to hostels on the opposite side of London. The report severely criticises the standard of communications and the passing of information between different agencies who were or "should have been" concerned with his care. But the obsessional detail in which this information is presented, and in which some individual carers are personally criticised, concentrates largely on individuals rather than the overall system of healthcare itself.

It must now be questioned whether the overall system of delivery of care was the appropriate model to deal with Clunis's needs and whether an alternative should have been considered, or indeed was available. The care plan approach (CPA) is now required to be implemented by all health authorities in the United Kingdom and the report has given considerable impetus to its installation. But it must be questioned whether this form of management is always appropriate for the most severely psychotic patient and the extent to which carers can rely on the CPA without a wide range of additional resources (Thornicroft et al, 1993). It must also be questioned whether carers have been adequately trained and prepared for the introduction of the CPA. One professional (whose practice is commented on adversely) suddenly found herself in the unacceptable position of named key worker for Clunis on a Section 117 form, completed at a meeting on the opposite side of London, at which she had not even been present. Similar passing on of responsibility without agreement from the recipient may not be uncommon practice (Britto \& Critchlow, 1994). The enquiry revealed at best a poor imitation of the CPA and at worst a parody. But its emphasis on the improvement of the CPA model, rather than the requirement that additional models should be available to clinicians in future, may ultimately prove a missed opportunity.

\section{Minimising the dangerousness}

The impending disaster and its portents in Clunis's history will not be missed by clinicians experienced in the assessment of dangerous psychotics. However, it was the committee of enquiry itself who were first to assemble the series of warnings of what was to come. Direct links between symptoms and subsequent criminal behaviour can often be observed within an individual patient's psychopathology, sometimes with repetition at times of exacerbation of symptoms, or during relapses. With benefit of hindsight, Clunis can be observed to have had a tendency to use bladed or pointed weapons in response to his delusional ideas, and to target his victim's head, in particular the eyes. He was found in possession of a cutlery knife in one hospital as far back as 1988 . He threatened to stab another patient in 1989 , on this occasion in his genitals, returning to the ward and stabbing him five times the following day while he lay in bed. The same year he returned to another hospital, after a day's leave, intending to stab another patient with whom he had quarrelled, this time in the eye. A few months later, in 1990, he tried to gouge out the eye of a fellow resident in a hostel. In March 1991, he chased other residents around another hostel with a carving knife. Later the same year he caused facial lacerations to another resident in a resettlement unit. In May 1992, he stabbed a resident in the neck in another hostel. Between these incidents he made several other assaults of a less specific nature. In the two weeks leading up to the offence. Clunis was not only floridly psychotic but potentially homicidal at any time. Several days before the killing, two incidents occurred which could easily have led to the death of another man or a child. The first involved an incident in which a man walking his dog was punched in the face, beneath his eye. Clunis was brandishing a screwdriver in his fist. He later chased boys around parked cars with the same weapon. Repeated contacts and telephone calls to the local police from victims and families failed to effect his removal from the community.

The enquiry observed a prolonged tendency to overlook or minimise these violent incidents and a fallure by a series of professionals to assess Christopher Clunis' past history of violence, or to assess his propensity for violence in the future. They also concluded that there was a tendency to postpone decisions or action when difficulty was encountered, perhaps because the patient was threatening and intimidating, "and possibly because he was big and black." This conclusion is not placed in its wider context. Psychiatric trainees and social workers do not require experience in assessing dangerous patients or clinical exposure to them before appointments to work in community settings. It is theoretically possible for a consultant to be appointed to an inner city service with little or no previous experience of managing patients detained under Part 3 of the Mental Health Act, 1983, or of assessing them in prison. Examination of psychiatrists for membership of the College does not include the Mental Health Act at the present time. Negative attitudes towards clinical responsibility for patients like Clunis are more likely in the absence of adequate training, and can manifest themselves through minimising, redefining, or rediagnosing the problem (Coid, 1988). This is further compounded by inadequate resources. 


\section{Shortage of resources}

The committee observed that when Clunis's lliness was at its most severe, and when his behaviour was most disturbed, catchment area psychiatric services did not have the resources avallable to them to cope with the patient. Beds in locked intensive care wards were full or simply did not exist, so that he had to be sent to other hospitals or else tranquillised with large quantities of anti-psychotic medication. On one occasion he was transferred to a distant private hospital when no bed was avallable in the local medium secure unit, further disrupting his continuity of care.

The committee drew attention to a serious shortage of medium secure, locked intensive care, and in the overall numbers of general psychiatric beds for the population of Inner London. In addition, they drew attention to an additional, serious shortage of a range of aftercare accommodation, especially for patients who cannot cope alone and are prone to relapse. They also noted a lack of Section 12 approved doctors and social workers trained and experienced in mental illness. But the committee did not examine in any detail the historical background or management policies which had led to these deficits. Over the last decade, Inner London has seen a progressive loss of acute admission beds, the closure of long stay beds in mental hospitals, and growing numbers of forensic patients placed in the private sector, many miles from patients homes.

\section{The reckoning for psychiatry}

The emphasis on improvement in clinical practice, rather than a radical rethinking of current policy, has been vigorously taken up by the Department of Health. This may leave psychiatrists dangerously exposed to increased personal stress in their jobs, blame for future failures, and at risk of litigation. The report criticises the Department of Health's previous advice on the care programme approach (CPA), describing it as "difficult to understand and couched in unhelpful jargon." It gives an alternative description of the CPA in its own words and the principles by which patients should be assessed prior to discharge and the care they should receive subsequently. Further improvements to aftercare under Section 117 of the Mental Health Act, 1983, are proposed, including a register, the provision of trained keyworkers, measures to improve the effectiveness of transfer of care when a patient moves, and the monitoring of aftercare subsequently received. Apart from steadily growing doubts that registers will be workable
(O'Connor et al, 1994), many of these proposals are clearly sound. But what is not adequately examined is whether these proposals can ultimately be realised.

The committee heard evidence that key workers should have ten patients as an average workload when dealing with the severely mentally 111 . But the Department of Health has issued no guidelines on the number of patients that individual community carers should be responsible for or the revenue implications. The report also proposes the introduction of new legislation in the form of a "supervised discharge order". This would enable the patient to be compulsory recalled to hospital if he or she fails to comply with the plan of discharge or where there is evidence of a deterioration in mental state in the community. But the recent failure to introduce "community supervision" Orders (House of Commons Health Committee, 1993) still leaves the CPA unworkable for the persistently unco-operative patient. The schedule for introducing the new legislation remains unclear and may fall yet again under pressure from the civil liberties lobby.

Several of the committee's recommendations have been taken up by the Department of Health and incorporated into a series of guidelines for the care and treatment of mentally ill persons discharged into the community (Department of Health, 1994). The implications of these guidelines, while entirely correct in their purpose of improving the care of the mentally ill in the community, may not be successfully realised by psychiatrists in the long term. The current context of a resource-starved discipline, in a time of considerable change and uncertainty, and where reality dictates that psychiatrists have little control over the behaviour of their patients when they leave hospital, has simply been ignored. Taking up these recommendations without simultaneously addressing resources has introduced a mechanism which allocates responsibility and identifies the recipient for blame for failure in the future, but diverts attention away from resource issues. The recently circulated draft guidelines specify quite clearly that in the circumstances of a suicide an internal enquiry must be considered and that following homicides enquiries are mandatory. Emphasis will be placed on examination of the exercise of judgment by the responsible professionals and the use of the resources available to those responsible, rather than the adequacy of those resources. It is reasonable to assume that the reports of these committees will be subpoenaed in the future by the legal representatives of victims and their families for the purposes of litigation against community carers who have failed. 


\section{Conclusion}

The enquiry concluded that Jonathan Zito died because the care and treatment Christopher Clunis received was a "catalogue of fallure and missed opportunity". It is fortunate that no single person, service, or agency was singled out for blame and that the problem was ultimately viewed as "cumulative." Disciplinary proceedings, increasingly the price of failure in the health service, cannot occur when there are simply too many healthcare professionals involved and where the buck never stopped. But the new guidelines will ensure that the buck stops in the future.

The committee heard evidence that there were many more patients like Christopher Clunis. The opposite must also be considered. Were the services, agencies, and professionals who failed Christopher Clunis inherently worse or substantially different from the rest? The possibility must be faced that the services found deficient by the enquiry are merely typical of psychiatric care throughout much of London and in many other parts of the country. The main importance of the Christopher Clunis enquiry is that it now poses very unpleasant questions about the ideology of healthcare delivery and the routine clinical management of severely mentally ill persons in the UK. It reveals a system in which many professionals are undertrained for the CPA, underresourced for its successful introduction, and where new guidelines on standards of care are being imposed without the means to achieve them. It inevitably questions whether unrealistic expectations of psychiatry have been fuelled by a small number of widely publicised, relatively well-resourced, model community services, but where the results of these experiments have so far failed to successfully translate into mainstream psychiatry. Christopher Clunis challenges some of the assumptions on which community psychiatry is currently based. His downward progress challenges not only the effectiveness but the relevance of community outreach services for a subgroup of severely mentally ill persons (Coid, 1991). His short stay in one in-patient service was also criticised severely in the report. Yet this was well in excess of the mean length of stay considered a hallmark of success in some experimental communitybased services. It cannot be routinely assumed
In the future that dangerousness has been adequately assessed in less than two weeks, or that schizophrenia has been adequately treated, without placing clinicians at some risk of litigation and disciplinary proceedings.

Jonathan Zito died because the ideology and organisation of mental health care services, the training of healthcare professionals, and the facilities available are simply inadequate for patients whose conditions remain intractable and render them uncooperative with care in the community. The legislation which might have ensured some chance of his receiving treatment outside of hospital does not exist. Furthermore, the type of in-patient facility that he truly needed has been closed in much of the UK. If ever a patient required prolonged institutional care it was Clunis. Sadly, it was only after he killed an innocent member of the public that he could receive it.

\section{References}

BRrTTO, D.J.J. \& CRrTChLow, G. (1994) Care programme approach in Shropshire District (letter). Psychiatric Bulletin, 18, 181-182.

CoID, J.W. (1988) Mentally abnormal offenders on remand: I. Rejected or accepted by the NHS? II. A comparison of services provided by Oxford and Wessex Reglons. British Medical Journal, 296, 1779-1784.

- (1991) "Difficult to place" psychiatric patients. British Medical Journal, 302, 603-604.

DEPARTMENT OF HEALTH (1994) Guidance on the discharge of mentally disordered people and their continuting care in the community. Draft Health Service Guidance/Local Authority Circular.

House of Commons Health COMmrtree (1993) Community Supervision Orders. Health Committee 5th Report. Vol 1. London: HMSO.

O'CONNOR, S., PARKer, J., MUMford, D., COOK, D.A. et al (1994) Supervision register needs rethinking (letter). British Medical Journal, 308, 1236-1237.

RITCHE. J.H., Dick, D. \& LINGHAM, R. (1994) The Report of the Inquiry into the Care and Treatment of Christopher Clunis. London: HMSO.

THORNICROFT, C., WARD, P. \& JAMES, S. (1993) Care management and health. British Medical Journal, 306, 768-771.

WATERHouse . R. \& Williams, R. (1993) Passing the buck carried on until an innocent man died. The Independent, 19 July, page 6.

Jeremy W. Coid, Senior Lecturer in Forensic Psychiatry, Department of Psychological Medicine, St Bartholomew's Hospital, London EC1 